\title{
Portanus Ball: descrição de uma espécie nova (Hemiptera, Cicadellidae, Xestocephalinae) ${ }^{1}$
}

\author{
Adenomar Neves de Carvalho ${ }^{2,3}$ \& Rodney Ramiro Cavichioli2,4
}

\author{
'Contribuição n ${ }^{\circ} 1417$ do Departamento de Zoologia, Universidade Federal do Paraná. \\ ${ }^{2}$ Departamento de Zoologia, Universidade Federal do Paraná. Caixa Postal 19020, 81531-980 Curitiba-PR, Brasil. Endereço \\ eletrônico: cavich@ufpr.br \\ ${ }^{3}$ Bolsista CAPES. Endereço eletrônico: adenomarc@yahoo.com.br \\ ${ }^{4}$ Bolsista CNPq.
}

\begin{abstract}
Portanus Ball: description of a new species (Hemiptera, Cicadellidae, Xestocephalinae). Portanus dubius sp. nov. is described and illustrated. The specimens were collected with Malaise trap during an entomological inventory in Paraná State, Brazil (PROFAUPAR).
\end{abstract}

KeYwords. Brazil; new species; Portanus; Xestocephalinae.

Resumo. Portanus dubius sp. nov. é descrita e ilustrada a partir de espécimens que foram coletados com armadilha Malaise durante um levantamento entomológico no Estado do Paraná, Brasil (PROFAUPAR).

Palavras-chave. Brasil; espécie nova; Portanus; Xestocephalinae.

Portanus Ball, 1932 é grupo diverso e relativamente abundante da família Cicadellidae com 49 espécies descritas (Carvalho \& Cavichioli 2003). Portanus e Xestocephalus Van Duzee, 1892 são gêneros de Xestocephalinae que ocorrem na América do Sul, onde existe grande carência de levantamentos entomofaunísticos. As espécies de Portanus foram estudadas por Linnavuori (1959), Kramer (1961, 1964), Delong (1980, 1982), Delong et al. (1980) e por Carvalho \& Cavichioli (2001, 2003). Neste estudo, uma espécie nova é descrita e ilustrada: Portanus dubius sp. nov., coletada durante o Projeto de Levantamento da Fauna Entomológica no Estado do Paraná (PROFAUPAR), conduzido por pesquisadores do Departamento de Zoologia da Universidade Federal do Paraná, durante os anos de 1986 a 1988.

O material-tipo está depositado na Coleção de Entomologia "Pe. J. S. Moure", Departamento de Zoologia, Universidade Federal do Paraná, Curitiba (DZUP).

\section{Portanus dubius sp. nov.}

(Figs. 1-13)

Diagnose. Pronoto com faixa branca em forma de "U" invertido na margem anterior. Pigóforo portando um par de processos pré-apicais bifurcados e espiniformes, ambos com um ramo curto voltado para cima, seguido por outro longo, agudo e direcionado para trás. Edeago subcilíndrico com um par de processos pré-apicais curtos e pontiagudos na margem dorsal.

Comprimento do corpo. Macho: 6,7 mm. Fêmea: 7,1 mm.

Coloração geral marrom-escura. Face e região da margem anterior da coroa esbranquiçada (Fig. 13); coroa preta com um par de manchas brancas circulares no ápice, entre os ocelos; margem posterior da coroa com estreita faixa branca irregular. Pronoto marrom-claro com uma faixa branca horizontal larga em forma de "U" invertido; com várias manchas esbranquiçadas irregulares. Asas anteriores marrom-escuras, subhialinas, com as veias da metade basal manchadas de branco; ápice das veias clavais com pequena mancha branca (Figs. 1, 12, 13).

Descrição. Cabeça, em vista dorsal, pouco pronunciada anteriormente; margem anterior da coroa arredondada, sem carena na transição com a face; superfície dorsal finamente pontuada; ocelos localizados na transição da coroa com a face, eqüidistantes dos olhos compostos e da linha mediana da coroa; sutura coronal alongada, atingindo a metade do comprimento mediano da coroa; fóveas tentoriais dorsais evidentes (Figs. 1, 12); sutura frontogenal tocando os ocelos; antenas tão longas quanto a metade do corpo.

Pronoto tão largo quanto a cabeça, convexo, finamente pontuado; margens ântero-laterais arredondadas, margem posterior retilínea (Figs. 1, 12). Asas anteriores com venação evanescente, exceto as do ápice; com três células anteapicais fechadas; terceira célula apical com o ápice alargado, a quarta subtriangular.

Pigóforo mais longo que a sua largura basal; margem inferior com um par de processos bifurcados e espiniformes na porção pré-apical, ambos com um ramo curto voltado para cima, seguido por outro longo, fortemente agudo e direcionado para trás; macrocerdas irregularmente distribuídas na margem superior e terço apical do pigóforo (Fig. 2). Placa subgenital triangular, bipartida com a porção apical estreitada; ápice arredondado e levemente curvado par cima; sem sulco transverso no terço basal; macrocerdas unisseriadas na porção 

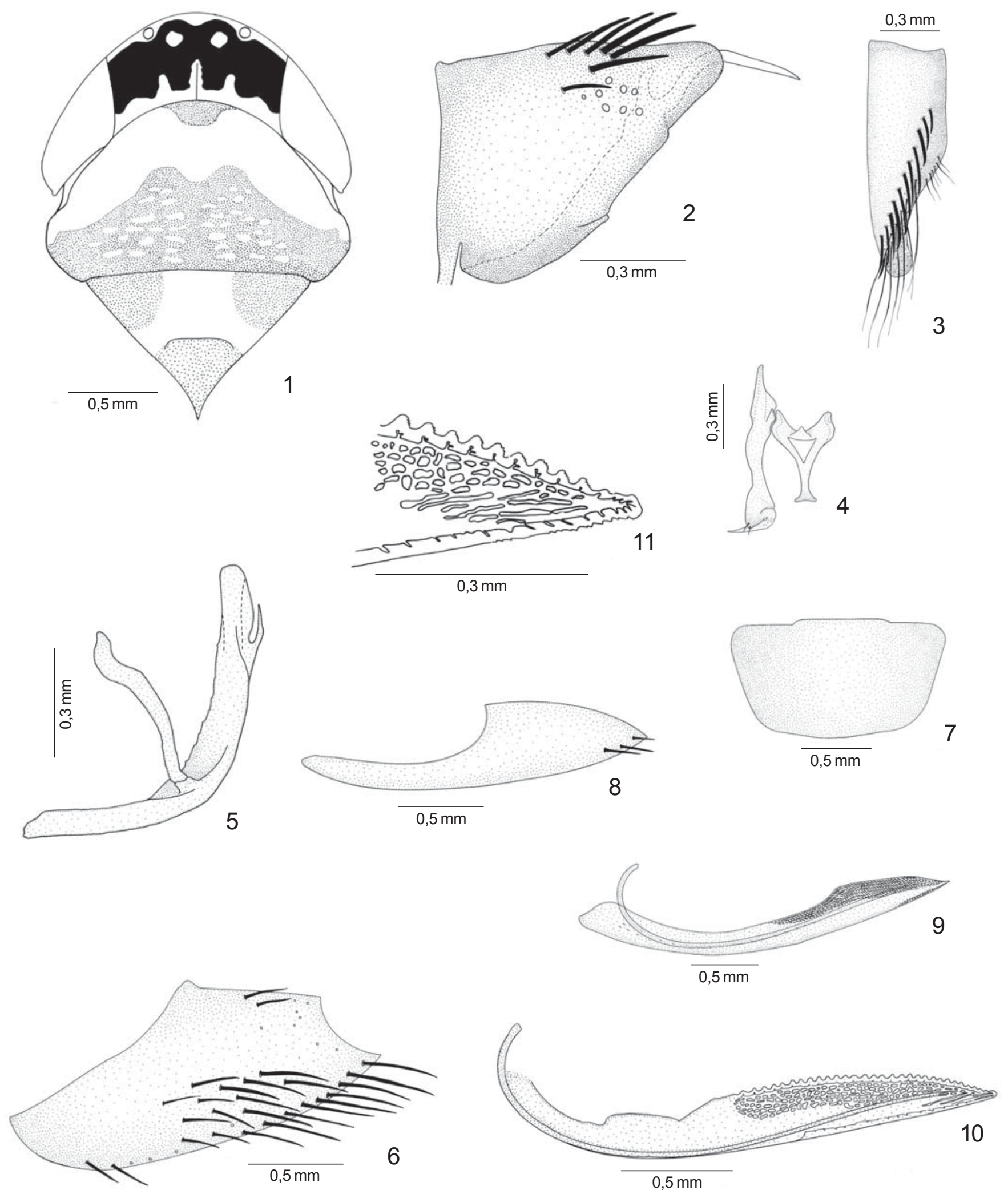

Figs. 1-11. Portanus dubius sp. nov.: 1, cabeça, pronoto e escutelo (vista dorsal); 2, pigóforo do macho (vista lateral); 3, placa subgenital, parte (vista ventral); 4, estilo e conetivo (vista ventral); 5, edeago (vista lateral); 6, pigóforo da fêmea (vista lateral); 7, VII esternito (vista ventral); 8, terceira valva do ovipositor (vista lateral); 9, primeira valva do ovipositor (vista lateral); 10, segunda valva do ovipositor (vista lateral); 11, porção apical da segunda valva mostrando dentes, dentículos e ductos (vista lateral). 

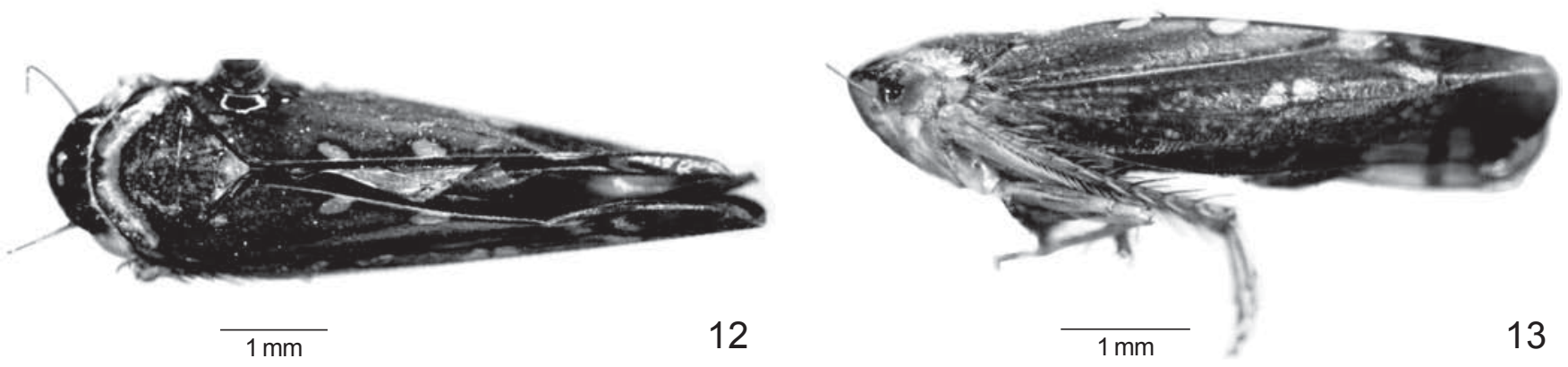

Figs. 12-13. Portanus dubius sp. nov.: 12, parátipo, vista dorsal; 13, holótipo, vista lateral.

mediana, cerdas longas e delgadas distribuídas irregularmente no ápice (Fig. 3). Estilos mais curtos que as placas subgenitais, estendendo-se além do ápice do conetivo, com o ápice alargado; apófise alongada, aguda e fortemente curvada lateralmente; lóbulo pré-apical triangularmente desenvolvido (Fig. 4). Conetivo em forma de "Y", com os braços mais curtos do que a haste (Fig. 4). Edeago alongado, com base estreita, portando um apódema no terço basal; haste subcilíndrica, levemente arqueada; margem anterior levemente serrilhada na porção mediana; margem posterior com um par de processos pré-apicais curtos e agudos direcionados para cima (Fig. 5); gonóporo apical.

Fêmea. Semelhante ao macho, porém, apresenta uma faixa horizontal preta na margem anterior da coroa. Pigóforo triangular, muito pronunciado posteriormente com uma concavidade apical, onde aloja o tubo anal; macrocerdas mais adensadas nas margens dorsal, ventral e apical; sem processos (Fig. 6). Esternito VII pouco pronunciado, mais largo do que longo; margem posterior aproximadamente retilínea (Fig. 7). Esternito VIII completamente membranoso. Valva I, longa, levemente alargada na porção pré-apical, estreitando-se para o ápice; cerdas diminutas ao longo de todo o comprimento da valva, sendo mais numerosas na porção basal; área esculturada dorsal estendendo-se do ápice à curvatura mediana (Fig. 9). Valva II, longa, expandida na porção mediana, estreitando-se para o ápice; superfície dorsal portando 29 dentes arredondados (Fig. 10), com vários dentículos na margem posterior; com ductos evidentes que se abrem em poros na base dos dentes e ápice da valva (Fig. 11). Valva III, longa, com ápice agudo; metade basal distintamente mais estreita que a apical; porção apical com um pequeno número de cerdas e diminutas estruturas espiniformes que se estendem para a base ao longo da margem ventral (Fig. 8).

Discussão. Portanus dubius sp. nov. externamente assemelha-se a $P$. vittatus Carvalho \& Cavichioli, 2003, no aspecto geral da coloração especialmente da coroa e pronoto.
Difere por apresentar a faixa branca na margem anterior do pronoto (em $P$. vittatus, está na porção mediana). A forma dos processos do pigóforo de $P$. dubius sp. nov. não se assemelham aos de qualquer outra espécie descrita no gênero.

Holótipo macho, BRASIL, Paraná: Ponta Grossa, 11.I.1988, Profaupar leg. (DZUP). Parátipos. Ibidem, 3 machos, 11.I.1988; 2 machos, 2 fêmeas, 4.I.1988, 2 fêmeas, 30.XI.1987, 2 fêmeas, 14.XII.1987, 1 macho, 22.II.1988, 1 macho, 18.I.1988, 1 macho, 16.XI.1987, Profaupar leg (DZUP). Guarapuava, 1 macho, 7.XII.1987, Profaupar leg. (DZUP).

\section{REFERÊNCIAS}

Carvalho, A. N. \& R. R. Cavichioli. 2001. Portanus Ball: descrições de cinco espécies novas (Hemiptera, Auchenorryncha, Cicadellidae, Xestocephalinae) do Mato Grosso, Brasil. Revista Brasileira de Zoologia 18(3): 855-867.

Carvalho, A. N. \& R. R. Cavichioli. 2003. Portanus Ball: descrições de dez espécies novas (Hemiptera, Cicadellidae, Xestocephalinae). Revista Brasileira de Entomologia 47(4): 547-558.

Delong, D. M. 1980. New South American Xestocephalinae leafhoppers (Homoptera: Cicadellidae). Entomological News 91(3): 79-84.

Delong, D. M. 1982. New species of Xestocephalinae (Homoptera: Cicadellidae) from Mexico, Panama, Peru and Brazil. Proceedings of the Entomological Society of Washington 84(2): 391-396.

Delong, D. M.; H. Wolda \& M. Estribi. 1980. The Xestocephalinae leafhoppers (Homoptera: Cicadellidae) known to occur in Panama. Brenesia 17: 251-280.

Kramer, J. P. 1961. New Venezuelan leafhoppers of the subfamilies Xestocephalinae and Neocoelidiinae (Homoptera: Cicadellidae). Proceedings of the Biological Society of Washington 74: 235-240.

Kramer, J. P. 1964. A key for Portanus with new records and descriptions of new species (Homoptera: Cicadellidae: Xestocephalinae). Proceedings of the Entomological Society of Washington 66(1): 5-11.

LinNavuORI, R. E. 1959. Revision of the Neotropical Deltocephalinae and some related subfamilies (Homoptera). Annales Zoologici Societatis Zoologicae Botanicae Fennicae 'Vanamo' 20(1): $45-51$. 